\title{
Poemas, de Alda Lara: \\ Para uma leitura da infância
}

\author{
Carla Ferreira ${ }^{1}$
}

RESUMO: Pretende-se neste texto realizar uma leitura dos poemas de Alda Lara privilegiando uma orientação em torno da temática da infância, colocando em relevo os modos como os poemas podem elaborar as vivências do passado e o contributo desse espaço geográfico para a construção do imaginário poético.

ABSTRACT: This text intends to carry out a reading of the poems by Alda Lara by privileging a direction around the theme of the childhood, putting in relief the ways as the poems express the existences of the past, and the contribution of this geographical space for the construction of the author's poetic imaginary.

PALAVRAS-CHAVE: Alda Lara; infância; espaço; imaginário.

KEYWORDS: Alda Lara; childhood; space; imaginary.

Sem desvalorizar as significações de sentido múltiplo estimuladas pelo conjunto da produção literária de Alda Lara ${ }^{2}$, interessamo-nos,

\footnotetext{
${ }^{1}$ Doutoranda em Ensino da Literatura, Universidade de Lisboa. Pesquisa: Ensino das Literaturas de Língua Portuguesa, Percursos da Narrativa. Email: carlalferreira@hotmail.com

2 Alda Pires Barreto de Lara e Albuquerque nasceu em Benguela em 1930 e veio a falecer em Cambambe em 1962. Foi aluna do Colégio de Paula Frassinetti de Sá da Bandeira e do Liceu D. Maria Amália Vaz de Carvalho em Lisboa. Frequentou as Faculdades de Medicina de Lisboa e de Coimbra, onde se licenciou e tendo-se associado nessa época a actividades diversas da Casa de Estudantes do Império. Regressou a Angola, onde exerceu medicina. Apesar de sua prematura morte, Alda Lara deixou-nos um trabalho literário de qualidade, sobretudo poético, mas também de narrativa curta, colaboração dispersa em vários periódicos, realização de conferências dentro da sua área profissional, tendo ainda revelado especial apetência pela actividade declamatória. A sua obra (Poemas, Sá da Bandeira: Imbondeiro, 1966 reeditado em Luanda e em Portugal, completado com textos inéditos até então; Tempo de Chuva [contos], Lobito, 1973), editada postumamente por Orlando de Albuquerque, seu marido e também escritor, não sendo muito extensa revela uma sensibilidade face ao desígnio do Homem Africano, aos valores de solidariedade humana e um fascínio contagiante por África.
} 
nesta reflexão ${ }^{3}$, por uma leitura orientada em torno da busca da profundidade humana compreendida nos seus poemas à luz do quadro de valores de uma ontologia africana. Neste prisma, a infância, bem como as condicionantes de tempo e espaço em torno das vivências desse período, revelam-se determinantes para o processo de consciencialização social do sujeito, através de um constante revisitar das referências do passado.

Definitivamente marcante para a linha poética seguida pela autora terá sido a sua deslocação para Portugal (então chamado de Metrópole) a fim de estudar medicina. O conhecimento de outros estudantes africanos em condições semelhantes e a crescente afinidade de ideais entre eles, o apelo por África avivado pela distância, a par do amadurecimento de alguns ideais, provocaram em Alda Lara uma percepção da consciência humana que podemos ver reflectida na sua obra. Assim, e também na linha dos objectivos visados pelo Movimento dos Novos Intelectuais de Angola ${ }^{4}$ entretanto formado em Luanda, o grupo de estudantes ${ }^{5}$ que se encontrava na Metrópole envolveu-se na fundação da Casa dos Estudantes do Império, responsável por uma certa agitação cultural da época e onde Alda Lara se empenhou de forma muito significativa, tanto pela filiação temática da sua poesia como pela atitude cívica anotada nas diversas intervenções culturais que protagonizou.

Assumindo o poder da palavra, a poesia desta geração pretende ensaiar a expressão de uma nova condição do Povo Africano,

\footnotetext{
3 Utilizamos, para este estudo, o volume Alda Lara, Poemas, Porto, Vertente, $4 .{ }^{\text {a }}$ ed., s/d. (1966), feito publicar postumamente por Orlando de Albuquerque.

4 "Em 1948, aqueles rapazes, negros, brancos e mestiços, que eram filhos do país e se tornavam homens, iniciam em Luanda o movimento cultural "Vamos descobrir Angola!". Que tinham em mente? Estudar a terra que lhes fora berço, a terra que eles tanto amavam e tão mal conheciam", p. 101; "Enquanto estudavam o mundo que os rodeia, o mundo angolano de que eles faziam parte mas que tão mal hes haviam ensinado, começa a germinar uma literatura que seria a expressão da sua maneira de sentir, o veículo das suas aspirações, uma literatura de combate pelo seu povo", p. 102. Cf. Carlos Ervedosa, Roteiro da Literatura Angolana, Cuba/UEA/Ediciones Cubanas, 1985.

5 Nesse tempo, viveram em Portugal, entre outros estudantes, jovens intelectuais, escritores, artistas e políticos, Agostinho Neto, Marcelino dos Santos, Carlos Ervedosa, Amílcar Cabral, Eduardo Mondlane, João Dias, Alda Espírito Santo, Noémia de Sousa.
} 
procurando veicular, mais intensamente a partir da década de sessenta e certamente encorajada pela realidade histórico-política da luta pelas independências nos diferentes espaços colonizados, a afirmação de uma identidade própria ${ }^{6}$.

\section{Criança, Ritmo, Poesia}

A recorrência temática do retorno à infância na produção literária da época, através de uma perspectiva afectiva, traduz o relevo atribuído ao espaço das origens e às vivências emotivas que nele ocorreram. Pelo exercício do pensamento e pela linguagem, os autores tentam representar momentos de um passado sentido como longínquo, mas de onde se liberta ainda o prazer de uma experiência autêntica. Neste sentir conjunto, de contornos indefinidos entre a alegria da lembrança, a sentida recompensa pela vivência do pretérito e a esperança futura, se enquadra a produção oriunda de cada uma das ex-colónias, entre as quais a de Angola e, particularmente, a de Alda Lara.

Os fundos temáticos tentam, pois, preconizar, a par da especificidade de cada realidade, a afirmação de novos valores, difundidos pela exposição de variadas linhas de sentido orientadoras, como nos refere, num estudo elucidativo e clarificador sobre a evolução histórica da Literatura Angolana, Alberto Carvalho:

Sob uma grande diversidade de tópicos, as tendências dominantes da maioria das produções poéticas da década de 50 referem-se, em primeiro lugar à reconstituição dos lugares-tempo que reestruturam a identificação infantil e juvenil urbanas dos sujeitos utentes da palavra desmistificadora. Em conjunto organiza um paradigma de poesia de 're-iniciação' e regresso à origem, a lugares-para-si cenários de candura, forjados por uma observação sensorial-sensual tão eufórica quanto ingénuo podia ser o olhar de menino.

Depois, sobre esta base positiva que mobiliza o corpo e, por isso, impregnada de jogos de ritmos que plasmam alguns efeitos da

\footnotetext{
${ }^{6}$ Para uma apreensão mais extensa e completa da actividade cultural, social e política desenvolvida pela Casa dos Estudantes do Império e do seu significado, cf. Pires Laranjeira, "Uma Casa de Mensagens Anti-Imperiais", in Ensaios Afro Literários, 2. ed., Lisboa, Novo Imbondeiro, 2005 (2001), p. 125-145.
} 
poesia oral, diversificam-se os discursos poéticos estilizados em diversos subgéneros que oscilam entre a hipostasia da individualidade de 'eu' e a solidariedade de 'nós'7.

Integrando-se neste perfil de significações, o retorno à infância concretiza-se, na poesia de Alda Lara, quer pela recuperação em alguns dos seus textos dos matizes de um discurso para a infância, característico das cantilenas e historietas, espelhando as marcas de uma oralidade evocadora das vivências, dos espaços e do tempo de uma inocência feliz quer, em outros poemas, pelo exercício de memória afectiva do ser criança a partir de uma perspectiva de reflexão presente, recorrentemente habitada pela angústia da distância. No entanto, à recuperação das formas poéticas associadas ao universo infanto-juvenil não corresponde, convém anotá-lo, necessariamente a inocência da mensagem poética; pelo contrário, os textos da autora apresentam um sujeito consciente da realidade e hábil na descrição impressiva desse contexto pelo recurso a um ritmo inspirado na oralidade associada à circulação de enunciados literários para o tempo de ser criança.

Entre outros ${ }^{8}$, "Poema da mesa pintada"9 , de 1950, ilustra esse percurso de chamamento, pela forma e cunho oralizante, do universo infantil que aqui referenciamos. Desde o verso inicial, "Eram três meninas sentadas"10, que o texto invoca o tradicional início de "era uma vez" dos contos para a infância. Estruturado segundo uma modulação narrativa, o poema exibe assim uma correspondência entre o ritmo e a mensagem de reconstrução dos momentos de brincadeiras entre três meninas. Apesar do tom narrativo e da enunciação não se situar na esfera do Eu, a inclusão da dedicatória "(às minhas primas: Maria Ana e Maria Ângela)" 11 pode favorecer uma leitura onde o sujeito se inclui, em

\footnotetext{
${ }^{7}$ Alberto Carvalho, "A Propósito de uma Historiografia Literária Angolana”, in Vértice, n. ${ }^{\circ}$ 55, II série, Jul/Ago, Lisboa, Caminho, 1993, p. 9-18, p. 16.

8 Dentro desta linha temática, e ainda que com matizes de outro conteúdo de significação, consideramos que devem também ser contemplados os poemas "Ronda", "Poemas que eu escrevi na areia", "As belas meninas pardas", e "Trampolim", inseridos respectivamente nas páginas $15,17,31,63$.

9 Alda Lara, Op. Cit., p. 23.

10 Idem, p. 23.

11 Ibidem.
} 
sentido de experiência biográfica, já que, de acordo com esta dedução, se contariam três meninas.

A utilização das formas verbais "eram", "passavam”, "cansavam”, "rasgavam", "trocavam" no pretérito imperfeito do indicativo, além de concorrer para a tonalidade narrativa do poema, contribui para o surgimento da sensação de permanência dos momentos do jogo no espírito do sujeito, que são, no texto, valorizados por uma conotação eufórica insinuada na selecção de lexemas como "sorrindo", "beleza", "bela", "sorrisos", "lendas", "amor", "bailando", simbolicamente referenciais de beleza e harmonia. Caracterizando positivamente a experiência da infância, estes elementos conferem a esta etapa um estatuto de gerador de felicidade, neste caso concretizado exemplarmente na descrição das brincadeiras das meninas/personagens do poema/história. Dentro deste entendimento, o retorno feliz ao passado enquadrar-se-á num exercício de afirmação ontológica, como o refere Gilbert Durand na conclusão de um estudo sobre as estruturas antropológicas do imaginário:

Bien loin d'être le résidu d'un déficit pragmatique, l'imaginaire nous est apparu tout au cours de cette étude comme la marque d'une vocation ontologique. Bien loin d'être épiphénomène passif, néantisation ou encore vaine contemplation d'un passé révolu, l'imaginaire non seulement s'est manifesté comme activité qui transforme le monde, comme imagination créatrice, mais surtout comme ordonnance de l'être aux ordres du meilleur ${ }^{12}$.

De facto, tratando-se de uma descrição de felicidade, cuja sugestão se reforça pela cadência rítmica do texto, também ela sugestiva de alegria e vivacidade, marcada por uma diversidade estrófica (composto por seis estrofes, respectivamente uma sétima, um terceto, uma sextilha e três dísticos), métrica (de trissílabos até octossílabos) e rimática (seguindo uma opção por verso livre e consequente irregularidade ao nivel da rima) e pulverizado de suspensões, a integração do passado no seio de uma reflexão presente

12 Cf. Gilbert Durand, Les Structures Anthropologiques de l'Imaginaire, Introduction à l'archétypologie générale, Grenoble, Imprimerie Allier, 1959, p. 466. 
demonstra como aqueles momentos habitam o sujeito para sempre, oferecendo-lhe uma base experiencial importante no contexto de um equilíbrio vital, encontrado nos interstícios entre o momento vivido, testemunhado e o tempo em que é rememorado. Através da leitura de uma vida outra, o leitor, narratário possível da história das brincadeiras das três meninas, pode também ele crescer no confronto com o seu próprio historial e imaginário pessoal, cumprindo assim a literatura um dos seus desígnios maiores, fazendo com que "un texte ne cesse jamais de se transformer et de transformer le lecteur"13, tornando-a especialmente enriquecedora no jogo do seu permanente "flux perpétuel d'images et de sons mêlés"14.

Tomando como marco fundamental para o desvendar das significações emanadas do texto a sua organização temporal, podemos assim dividi-lo em dois momentos: um, compreendendo as três primeiras estrofes e um outro incluindo os três dísticos finais. $\mathrm{Na}$ primeira parte, desenha-se, como atrás expressámos, o passar dos dias felizes da infância das três meninas, e na segunda, interroga-se o seu destino posterior, sugerindo apenas que aqueles instantes terminaram e, também, depreende-se, a cumplicidade e o espírito de comunidade então sentidos.

A anotação do pretérito emerge dentro de um sentido particularizante em torno de um objecto material - a mesa - que sofre uma transfiguração do seu estatuto comum de utensílio/instrumento utilitário para brinquedo/elemento fútil, revalorizando-se nesta dupla funcionalidade de união entre o mundo prático e o universo do jogo onde, por força da imaginação infantil que tudo transforma, adquire uma revalorização, sinal do poder e vitalidade daquela. O valor deíctico da especificação da mesa expresso nos versos "à volta daquela mesa, / da bela mesa pintada"15, nomeadamente do determinante demonstrativo, associa o sujeito aos momentos invocados pelo texto,

\footnotetext{
13 François Laplantine, Je, nous et les autres, Être humain au-delà des appartenances, Paris, Éditions Le Pommier, 1999, p. 80.

14 Ibidem.

15 Alda Lara, Ibidem.
} 
implicando-o na experiência descrita e na sequente perplexidade do presente.

A interrogação "foi o sonho que as levou?"16 indicia, desde logo, a separação, questionando-se o sujeito relativamente às razões subjacentes à nova realidade, chegada com o desfazer do passado comum, e onde reina agora a incerteza e busca de respostas, como nos aponta a segunda pergunta "ou foi a vida, enganada?...”. A estrutura de alternância que relaciona ambos os versos, alude à incompreensão do presente, aparentemente surpreendente na perspectiva do sujeito. Na sua alma, e apesar da partida/separação das amizades infantis, habita ainda o pretérito, agora transfigurado sob a forma de "três sombras brancas”, elemento substitutivo das meninas, mas cuja presença pode enunciar uma significação positiva, de esperança, desvendada pelo verso final "bailando nas madrugadas", dentro do ritmo encantatório recuperado pelas suspensões, repetições e coloquialidade do texto.

\section{Infância, Experiência, Perplexidade}

No labor de reconstituição dos lugares-tempo da infância, os textos de Alda Lara não deixam de associar, à felicidade do passado, a experiência da perplexidade do presente, dividida entre o desejo de um regresso e a dor do afastamento. Longe de uma evocação simples da candura outrora vivida, anota-se frequentemente uma certa obsessão pela terra - já não apenas como local do jogo e da ingenuidade, mas igualmente como espaço de esperança, capaz de despertar o Homem para os valores de humanidade, como a solidariedade e fraternidade.

Por este rumo seguem, a nosso ver, e com especial força significativa, os poemas "Quadras da minha solidão","Presença Africana","Regresso", "Rumo", "Mar", “O grande poema” e "O poema da nostalgia"17. Apresentando como matriz comum a nostalgia do passado infantil de África e o desejo do regresso, os textos consagram uma nova

17 Idem, respectivamente nas p. 54, 57-58, 73-74, 79, 153, 155 e 157. 
dimensão em torno do lexema "terra", elemento integrante do imaginário da autora.

Após a consciencialização impulsionada pela distância, a "terra" apresenta-se como um espaço propício ao exercício de um profundo sentido de humanidade, despertando o sonho de uma pátria outra, de divergências esbatidas, nomeadamente as que norteiam a sociedade entre as dicotomias de pobre/rico e negro/branco, como bem o fundamentam os versos "Nela, /o mesmo sol ardente nos queimou / a mesma lua triste nos acariciou, / e se tu és negro, / e eu sou branca, / a mesma Terra nos gerou"18. Neste novo enquadramento, o sol, metáfora da pátria, deverá acolher a todos de igual modo, homenageando o sentido de igualdade com que todos gerou, independentemente da origem racial.

Relembrar a infância à distância do tempo e do espaço, recorrendo ao poder da representação da consciência ${ }^{19}$, implica sobretudo descobrir a diferença entre os universos africano e europeu, pertencendo ao primeiro o consolo telúrico e ao segundo o desconforto do desapego, numa evidente inadaptação e inconformidade do sujeito, como nos revelam os versos "Fica longe o sol que vi, / aquecer meu corpo outrora... / Como é breve o sol daqui! / e como é longa esta hora..."20. Esta viagem ao passado da infância contribui, segundo Laplantine, para um processo de autoconhecimento do sujeito, auxiliando-o na busca da sua identidade e na qual se integram os lugares/tempos infantis:

\footnotetext{
18 Alda Lara, "Rumo”, Idem, p. 79.

19 Cf. Gilbert Durand, L'Imagination Symbolique, Paris, PUF, 1964 : "La conscience dispose de deux manières pour se représenter le monde. L'une directe, dans laquelle la chose elle-même semble présente à l'esprit, comme dans la perception ou la simple sensation. L'autre indirecte lorsque, pour une raison ou pour une autre, la chose ne / peut se présenter 'en chair et en os' à la sensibilité, comme par exemple dans le souvenir de notre enfance, dans l'imagination des paysages de la planète Mars, dans l'intelligence de la ronde des électrons autour du noyau atomique ou dans la représentation d'un au-delà de la mort. Dans tous ces cas de conscience indirecte, l'objet absent est re-présenté à la conscience par une image, au sens très large de ce terme", p. 3-4.

20 Alda Lara,“Quadras da minha solidão”, Idem, p. 54.
} 
En renvoyant chaque individu ou chaque culture à une appartenance, l'identité leur désigne leur origine. Elle attire l'attention sur ce qu'il y a de plus stable et de plus permanent dans un être humain ou dans un groupe social, appréhendés à partir de ce qu'ils étaient autrefois, et non de ce qu'ils sont en train de devenir. L'identité conduit à s'identifier à, au point de coïncider avec un état révolu du sujet et du social. Dans ces pensées en marche arrière, on avance pour ainsi dire "à rebours" du temps. En valorisant ce qui est atavique, on revient abruti de racines.

Ce qui est recherché dans l'identité, qui a presque toujours un caractère grégaire, c'est l'hérédité, la race, le sang, le sol, l'enracinement dans la nation, la famille, la naissance, le déterminisme de l'ascendance voire de la couleur de la peau. La revendication identitaire, qui est une proclamation d'"autochtonie" et d'«authenticité», est revendication d'un reflux ${ }^{21}$.

A pontuação suspensiva e exclamativa, frequentemente utilizada, atribui aos textos um registo de mágoa e nostalgia que o sujeito poético não consegue evitar e que se tornou obsessivo com a experiência do distanciamento.

O sentido de esperança e o desejo de envolvência na construção de uma nova nação, motivados pelo incontornável apelo da terra, conferem à pátria de nascimento uma força aglutinadora de valores de autenticidade humana, a par do exotismo celebrado da paisagem geográfica, presente ao longo dos textos, e que preenchem o imaginário simbólico do $\mathrm{Eu}^{22}$, ilustrado, por exemplo, nos versos "Terra das acácias, dos dongos, / dos cólios baloiçando, mansamente ... / Terra!"23. A paisagem africana, habitando para sempre o sujeito, adquire no seu espírito uma vivacidade simbólica, concorrendo também para a crescente necessidade de voltar.

\footnotetext{
21 François Laplantine, Op. Cit., p. 41.

22 Cf. Alfredo Margarido, "Esboço de interpretação da poesia de Alda Lara, in Estudos sobre Literaturas das Nações Africanas de Língua Portuguesa, Lisboa, A Regra do Jogo, 1980, pp. 299-307: "E o facto de ter abandonado Benguela muito cedo para fazer em Lisboa e em Coimbra o seu curso de medicina, iria deixar-lhe na retina o canto rubro e incendiado (para alguns poetas angolanos também incendiário) das acácias das ruas de S. Filipe de Benguela, os cólios e os coqueiros e também a imagem dos quintalões benguelenses, que eram ainda o compromisso entre uma cultura que procurava assentar as suas bases numa efectiva mestiçagem e o despontar de atitudes mais rígidas entre as etnias (que a rápida valorização dos 'produtos coloniais', nos anos seguintes a 1945 firmou definitivamente) que hoje são moeda corrente”, p. 301.

23 Alda Lara, "Presença africana”, Idem, p. 57-58.
} 
O poema "Regresso"24 configura-se, na nossa opinião, como especialmente demonstrativo da constante presença de África no espírito do sujeito. Iniciando-se com a expressão de uma hipótese/esperança/projecto - "Quando eu voltar” -, a força da ligação telúrica do sujeito ao espaço das origens segue, ao longo do texto, um percurso de exaltação até se consagrar na decisão inquestionável anunciada nos versos "Sim! Eu hei-de voltar, / tenho de voltar, / não há nada que mo impeça”. A inevitabilidade desta certeza dá-se a perceber pela subjectividade do retrato elaborado das diferentes realidades - a africana/angolana, associada a uma percepção positiva da vida, e a europeia/portuguesa, congregadora de conotações disfóricas sentidas pelo sujeito.

Toda a expectativa em torno do regresso transporta o sujeito para uma antecipação imaginária das sensações a experimentar nesse momento, marcadas, no poema, pela subjectividade: "Ver de novo baloiçar / a fronde majestosa das palmeiras / que as derradeiras horas do dia, / circundam de magia... / (oh!... minha terra!...) / aquele odor escaldante / que o húmus vivificante / do teu solo encerra ! Embriagar / uma vez mais o olhar, / numa alegria selvagem, / com o tom da tua passagem, /que o sol, /a dardejar calor, / transforma num inferno de cor..."25. Não se trata apenas de desenhar uma geografia, mas sim de descrever uma completa entrega, como o designam as expressões "majestosa”, “escaldante”, "vivificante”, “embriagar”, "alegria selvagem”, "dardejar calor" e "inferno de cor", que indiciam a relação emotiva estabelecida entre sujeito e terra, favorecida pela sucessão de elementos sensoriais, dentro de uma cosmogonia só compreendida à luz de um passado marcante que permanece para sempre no sujeito, revelando-se na linguagem metafórica, que exterioriza a memória habitada do sujeito.

Em oposição, surge um tom de negatividade, fortemente reforçado pela dupla negativa "não mais" antecedendo cada elemento descritivo 
referente à Metrópole, atingindo-a nos elementos tipicamente caracterizadores da sua singularidade e revelando a desoladora experiência do Eu nesse espaço: "Não mais o pregão das varinas, / nem o ar monótono, igual, / do casario plano... / [...] / Não mais o agitar fremente / de uma cidade em convulsão ... / não mais esta visão / nem o crepitar mordente / destes ruídos”26. As sensações decorrentes do sentido ocular, auditivo e olfactivo constituem em tudo uma vivência antitética face ao imaginário espacial da infância do sujeito.

Antevendo o regresso, o Eu imagina, em tom apoteótico, uma natureza humanizada, sangrando as acácias rubras e gritando o esplendoroso, quente e ardente sol, como que celebrando e anunciando em conjunto esse desejado reencontro.

Interpretando os sentidos emergentes da leitura da poesia de Alda Lara, poderemos confirmar a importância das origens - nomeadamente as experiências associadas à infância e aos seus espaços - no condicionamento do posicionamento do ser humano em relação ao seu presente e na constituição de uma moldura de utopia e sonho capaz de guiá-lo na descoberta da essência da vida.

Referências Bibliográficas:

A) BIBLIOGRAFIA ACTIVA:

LARA, Alda. Poemas. 4. ${ }^{\text {e }}$ ed. Porto: Vertente, s/d. (1966).

B) BIBLIOGRAFIA PASSIVA:

ANDRADE, Costa. Literatura Angolana (Opiniões). Lisboa: Edições 70, 1980.

BRODEUR, Claude. L'Espace Africain. Paris: L'Harmattan, 1997.

CARVALHO, Alberto. A Propósito de uma Historiografia Literária Angolana. In Vértice n. ${ }^{\circ}$ 55, Lisboa, Caminho: II série, 9-18, Jul/Ago 1993.

DURAND, Gilbert. Les Structures Anthropologiques de l'Imaginaire, Introduction à l'archétypologie générale. Grenoble :Imprimerie Allier, 1959. . L'Imagination Symbolique. Paris: PUF, 1964.

ERVEDOSA, Carlos. Roteiro da Literatura Angolana. Cuba: UEA/Ediciones Cubanas, 1985. 
JEAN, Georges. Pour une pédagogie de l'imaginaire. 2. ${ }^{\mathrm{a}} \mathrm{ed}$. Tournai : Casterman, 1978 (1976).

LAPLANTINE, François. Je, Nous et les Autres, Être humain au-delà des appartenances. Paris : Éditions le Pommier, 1999.

LARANJEIRA, Pires. Uma Casa de mensagens Anti-Imperiais. In Ensaios Afro Literários. Lisboa: Novo Imbondeiro, 2005 (2001), 2. ${ }^{a}$ ed., p. 125-145.

MARGARIDO, Alfredo. Esboço de interpretação da poesia de Alda Lara. In Estudos sobre Literaturas das Nações Africanas de Língua Portuguesa. Lisboa: A Regra do Jogo, 1980, p. 299-307.

PIAGET, Jean. La Construction du réel chez l'enfant. 2. ${ }^{\mathrm{a}} \mathrm{ed}$. Neuchatel : Delachaux et Niestlé S.A., 1950. 